\title{
Risk of surgical site infection and efficacy of antibiotic prophylaxis: a cohort study of appendectomy patients in Thailand Nongyao Kasatpibal*1,2, Mette Nørgaard ${ }^{1}$, Henrik Toft Sørensen ${ }^{1}$, Henrik Carl Schønheyder ${ }^{3}$, Silom Jamulitrat ${ }^{4}$ and Virasakdi Chongsuvivatwong 5
}

\begin{abstract}
Address: ${ }^{1}$ Department of Clinical Epidemiology, Aarhus University Hospital, Aalborg and Aarhus, Denmark, ${ }^{2}$ Department of Fundamental Nursing, Faculty of Nursing, Chiang Mai University, Chiang Mai, Thailand, ${ }^{3}$ Department of Clinical Microbiology, Aalborg Hospital, Aarhus University Hospital, Aalborg, Denmark, ${ }^{4}$ Department of Community Medicine, Faculty of Medicine, Prince of Songkla University, Hat Yai, Songkhla, Thailand and ${ }^{5}$ Epidemiology Unit, Faculty of Medicine, Prince of Songkla University, Hat Yai, Songkhla, Thailand

Email: Nongyao Kasatpibal* - nongyaok2003@yahoo.com; Mette Nørgaard - aas.uxmeno@nja.dk; Henrik Toft Sørensen - hts@dce.au.dk; Henrik Carl Schønheyder - aas.hqkm@nja.dk; Silom Jamulitrat - ic_conference@yahoo.com;

Virasakdi Chongsuvivatwong - cvirasak@medicine.psu.ac.th

* Corresponding author
\end{abstract}

Published: 12 July 2006

BMC Infectious Diseases 2006, 6:III doi:10.1 186/147I-2334-6-III
Received: 14 April 2006

Accepted: 12 July 2006

This article is available from: http://www.biomedcentral.com/I47I-2334/6/II I

(c) 2006 Kasatpibal et al; licensee BioMed Central Ltd.

This is an Open Access article distributed under the terms of the Creative Commons Attribution License (http://creativecommons.org/licenses/by/2.0), which permits unrestricted use, distribution, and reproduction in any medium, provided the original work is properly cited.

\begin{abstract}
Background: No data currently exist about use of antibiotics to prevent surgical site infections (SSI) among patients undergoing appendectomy in Thailand. We therefore examined risk factors, use, and efficacy of prophylactic antibiotics for surgical site infection SSI among patients with uncomplicated open appendectomy.
\end{abstract}

Methods: From July I, 2003 to June 30, 2004 we conducted a prospective cohort study in eight hospitals in Thailand. We used the National Nosocomial Infection Surveillance (NNIS) system criteria to identify SSI associated with appendectomy. We used logistic regression analysis to obtain relative risk estimates for predictors of SSI.

Results: Among 2139 appendectomy patients, we identified 26 SSIs, yielding a SSI rate of 1.2 infections/ $/ 00$ operations. Ninety-two percent of all patients $(95 \% \mathrm{Cl}, 91.0-93.3)$ received antibiotic prophylaxis. Metronidazole and gentamicin were the two most common antibiotic agents, with a combined single dose administered in $39 \%$ of cases. In $54 \%$ of cases, antibiotic prophylaxis was administered for one day. We found that a prolonged duration of operation was significantly associated with an increased SSI risk. Antibiotic prophylaxis was significantly associated with a decreased risk of SSI regardless of whether the antibiotic was administered preoperatively or intraoperatively. Compared with no antibiotic prophylaxis, SSI relative risks for combined singledose of metronidazole and gentamicin, one-day prophylaxis, and multiple-day antibiotic prophylaxis were $0.28(0.09-0.90), 0.30(0.11-0.88)$ and $0.32(0.10-0.98)$, respectively.

Conclusion: Single-dose combination of metronidazole and gentamicin seems sufficient to reduce SSIs in uncomplicated appendicitis patients despite whether the antibiotic was administered preoperatively or intraoperatively. 


\section{Background}

Data regarding risk factors and use of antibiotics in surgical patients are essential for preventing and treating surgical site infections (SSI). Appendectomy is one of the most common surgical procedures [1] with SSI complicating 1$5 \%$ of appendectomy cases [2-4]. One established risk factor for SSI in appendectomy is the duration of operation [1].

While antibiotic prophylaxis is common in surgical procedures [5], inappropriate use of antibiotics occurs in 25$50 \%$ of general elective surgeries [6-10]. The efficacy of antibiotic prophylaxis in patients undergoing appendectomy has been examined in several randomized and observational studies [4,11-19] showing that appropriate use of antibiotics reduces the risk of SSI following appendectomy by $40-60 \%$.

In Thailand, some hospitals had their own internal antibiotic prophylaxis guidelines. However, standardized national guidelines for antibiotic prophylaxis among appendectomy patients have not yet been established. Simple appendicitis is treated according to surgeons' discretion, which results in use of many different agents.

No study has been conducted of the efficacy of antibiotic prophylaxis on risk of SSI in patients undergoing appendectomy in Thailand. We aimed to examine risk factors for SSI, the use of antibiotic prophylaxis, and the efficacy of antibiotic prophylaxis in reducing SSI among appendectomy patients in Thailand.

\section{Methods}

This prospective multicenter cohort study was conducted from 1 July 2003 to 30 June 2004 in eight Thai hospitals (four tertiary care teaching hospitals and four geographically dispersed general hospitals). The participating hospitals were Chiangkham Hospital, Saraburi Hospital, Bhumibol Adulyadej Hospital, Vachira Phuket Hospital, Naradhiwas Rajanagarindra Hospital, Rayong Hospital, Chumphon Khet Udomsakdi Hospital, and Udonthani Hospital. The project was approved by the Ethical Review Committee for Research in Human Subjects, the Thai Ministry of Public Health, and the Ethical Committee and/or the directors of the participating hospitals. After attending a one-day training session on data collection and diagnostic criteria, infection control nurses in each hospital prospectively collected and recorded data.

Operating room (OR) logbooks were reviewed daily to identify uncomplicated open appendectomies meeting the inclusion criteria. We excluded appendectomies incidental to other operative procedures and the patients who were on antibiotic therapy. Patients' names, hospital numbers, and wards were identified via OR records. Med- ical records, operative notes, anesthetic records, diagnostic imaging reports, microbiological and biochemical data, and data on the operative procedure (duration and type of operation) were reviewed by study nurses and attending physicians. The American Society of Anesthesiologists (ASA) score of patient physical status was abstracted from anesthetic records. Data on the use of antibiotic prophylaxis included timing of first antibiotic prophylaxis dose, antibiotic agent, and duration of antibiotic therapy. These were obtained from patients' medical and anesthetic records. Following review, pertinent data were recorded on preprinted data collection forms.

Outpatient records of discharged patients and medical records of readmitted patients were also reviewed for evidence of infections developing after hospital discharge. Completed data collection forms were edited and analyzed at the study data processing center.

\section{Definitions}

We used criteria of the US Centers for Disease Control and Prevention (CDC) NNIS System to diagnose SSI. Infections were classified as superficial incisional, deep incisional, or organ/space SSI [20]. The ASA score was used to characterize the patients' physical status as 1 (healthy), 2 (mild systemic disease), 3 (severe systemic disease), 4 (severe life-threatening systemic disease), or 5 (moribund) [21]. Patients' final diagnoses and operations were coded according to the International Classification of Diseases 10th Revision (ICD-10) and the International Classification of Diseases 9th Revision, Clinical Modification (ICD-9 CM), respectively. The appendectomy procedures were also classified according to the NNIS [22].

We defined uncomplicated appendicitis as acutely inflamed appendicitis without perforation (clean-contaminated wound). Patients with gangrenous appendicitis, peritonitis, or abscess formation were not included.

\section{Statistical analysis}

The rate of SSI was computed by dividing the number of infections by the number of operations performed and multiplying by one hundred.

Contingency tables were constructed to analyze the relations between SSI and the other study variables: use and duration of antibiotic prophylaxis, sex, age, length of preoperative stay, type of operation, ASA score, and duration of operation. We conducted logistic regression analysis to estimate the relative risk (RR) of SSI for the main study variables.

All analyses were performed using STATA statistical software, version 7 (Stata Corp, College Station, TX). 


\section{Results}

\section{Patient and operation characteristics}

During the study period, 2139 patients, 53.1\% of them women, underwent open appendectomy. The median age was 26 years (interquartile range 16 to 39). Twenty-one percent of patients were hospitalized preoperatively with a median length of preoperative stay of 1 day (interquartile range 1 to 1 ). For postoperative or total hospital stay, median length was 3 days (interquartile range 2 to 4 ). Among 2139 operations, 72.4\% were classified as emergency. The median operation duration was 58 minutes (interquartile range 42 to 83 ).

\section{SSI rates}

Twenty-six SSIs were identified in 2139 operations, yielding an overall SSI rate of 1.2 infections/100 operations. Superficial and deep incisional SSIs occurred most frequently (46.2\% each). Of the 26 SSIs, 15 (57.7\%) were detected after hospital discharge, and a half, within seven days after surgery. The median onset of SSI was 8 days (interquartile range 5-11).

\section{Risk factors}

The following variables were associated with the risk of SSI in the crude analyses: duration of antibiotic prophylaxis, age, elevated ASA score, prolonged preoperative hospital stay, duration of operation, emergency surgery, and sex. However, after adjustment, only prolonged duration of operation remained significantly associated with an increased risk of SSI ( $R R=3.29 ; 95 \%$ CI 1.44-7.52) (Table $1)$.

\section{The use of antibiotic prophylaxis}

Prophylactic antibiotics were administered in the course of $1972 / 2139(92.2 \%)$ operations. In $89.8 \%$ of these cases, antibiotics were given preoperatively, but they were given within one hour before the incision in only $38.9 \%$ of cases. The most common prophylactic antibiotics were metronidazole and gentamicin (64.2\%). The combination of a single dose of metronidazole and gentamicin was used in $38.8 \%$ of cases. Antibiotic prophylaxis was administered for one day in $54.2 \%$ of cases. The median duration of antibiotic prophylaxis was 1 day (interquartile range 1 to 2). Antibiotic prophylaxis was extended for over one day in $38.0 \%$ of patients (Table 2 ).

The doses of antibiotic prophylaxis administrated in this study were metronidazole $500 \mathrm{mg}$, gentamicin $80 \mathrm{mg}$, penicillin 2 million units, amoxicillin $500 \mathrm{mg}$, amoxicillin/clavulanate $1.2 \mathrm{~g}$, ampicillin $1 \mathrm{~g}$, cloxacillin $1 \mathrm{~g}$, cefazolin $1 \mathrm{~g}$, cephalexin $1 \mathrm{~g}$, cefotaxime $1 \mathrm{~g}$, ceftriaxone 2 $\mathrm{g}$, ceftazidime $1 \mathrm{~g}$, cefdinir $100 \mathrm{mg}$, cefoxitin $1 \mathrm{~g}$, ofloxacin $200 \mathrm{mg}$, norfloxacin $400 \mathrm{mg}$, cotrimoxazole $480 \mathrm{mg}$, chloramphenical $1 \mathrm{~g}$, fosfomycin $1 \mathrm{~g}$, clindamycin 600 $\mathrm{mg}$, and amikacin $500 \mathrm{mg}$.

Table I: The association between selected risk factors and surgical site infections

\begin{tabular}{|c|c|c|c|c|c|c|c|}
\hline \multirow[t]{2}{*}{ Risk factors } & \multirow[t]{2}{*}{$\mathbf{N}$} & \multirow[t]{2}{*}{ Infection } & \multirow[t]{2}{*}{ Rate* } & \multicolumn{4}{|c|}{ Relative risk } \\
\hline & & & & Crude & $95 \% \mathrm{Cl}$ & Adjusted** & $95 \% \mathrm{Cl}$ \\
\hline \multicolumn{8}{|l|}{$\begin{array}{l}\text { Duration of } \\
\text { antibiotic } \\
\text { prophylaxis }\end{array}$} \\
\hline None & 167 & 5 & 3.0 & 1.00 & Reference & 1.00 & Reference \\
\hline I day & 1159 & 12 & 1.0 & 0.34 & $0.12-0.97$ & 0.30 & $0.10-0.89$ \\
\hline$>$ I day & 813 & 9 & 1.1 & 0.36 & $0.12-1.09$ & 0.29 & $0.09-0.92$ \\
\hline \multicolumn{8}{|l|}{$\begin{array}{l}\text { Duration of } \\
\text { operation }\end{array}$} \\
\hline$\leq 1.0$ hour & 1738 & 16 & 0.9 & 1.00 & Reference & 1.00 & Reference \\
\hline$>1.0$ hour & 401 & 10 & 2.5 & 2.75 & $1.24-6.11$ & 3.29 & I.44-7.52 \\
\hline \multicolumn{8}{|l|}{ Age } \\
\hline I-20 years & 808 & 6 & 0.7 & 1.00 & Reference & 1.00 & Reference \\
\hline $21-40$ years & 853 & 14 & 1.6 & 2.23 & $0.85-5.83$ & 2.15 & $0.82-5.68$ \\
\hline $4 I-60$ years & 382 & 5 & 1.3 & 1.77 & $0.54-5.85$ & 1.91 & $0.57-6.48$ \\
\hline$>60$ years & 96 & I & 1.0 & 1.41 & $0.17-11.81$ & 2.11 & $0.22-20.76$ \\
\hline \multicolumn{8}{|l|}{$\begin{array}{l}\text { Type of } \\
\text { operation }\end{array}$} \\
\hline Elective & 591 & 9 & 1.5 & 1.00 & Reference & 1.00 & Reference \\
\hline Emergency & 1548 & 17 & I.I & 0.72 & $0.32-1.62$ & 0.78 & $0.33-1.83$ \\
\hline Total & 2139 & 26 & 1.2 & - & - & - & - \\
\hline
\end{tabular}

* Rate $=$ \# infections/100 operations

**Adjusted for sex, age, length of preoperative stay, type of operation, ASA score, and duration of operation 
Table 2: Characteristics of antibiotic prophylaxis administration

\begin{tabular}{|c|c|c|c|c|}
\hline Characteristics & Number & $\%$ & Infection & Rate* \\
\hline \multicolumn{5}{|l|}{ Antibiotic prophylaxis $(\mathrm{N}=2139)$} \\
\hline No & 167 & 7.8 & 5 & 3.0 \\
\hline Yes & 1972 & 92.2 & 21 & 1.1 \\
\hline \multicolumn{5}{|l|}{ Time of first antibiotic dose administration $(\mathrm{N}=1972)$} \\
\hline$>$ I hour preoperatively & 1004 & 50.9 & 8 & 0.8 \\
\hline$\leq \mathrm{I}$ hour preoperatively & 767 & 38.9 & 9 & 1.2 \\
\hline Intraoperatively & 47 & 2.4 & 0 & 0.0 \\
\hline Postoperatively & 154 & 7.8 & 4 & 2.6 \\
\hline \multicolumn{5}{|l|}{ Antibiotic agent $(N=1972)$} \\
\hline Combination Metronidazole and Gentamicin & 1266 & 64.2 & 13 & 1.0 \\
\hline Single dose combination & 766 & 38.8 & 8 & 1.0 \\
\hline Combination within I day & 130 & 6.6 & I & 0.8 \\
\hline Combination $>$ I day & 370 & 18.8 & 4 & 1.1 \\
\hline Others** & 706 & 35.8 & 8 & 1.1 \\
\hline Single dose & 108 & 5.5 & 2 & 1.9 \\
\hline Multiple dose or combination within I day & 155 & 7.9 & I & 0.6 \\
\hline Combination $>$ I day & 443 & 22.4 & 5 & 1.1 \\
\hline \multicolumn{5}{|l|}{ Duration of antibiotic prophylaxis $* * *(\mathrm{~N}=2139)$} \\
\hline None & 167 & 7.8 & 5 & 3.0 \\
\hline I day & 1159 & 54.2 & 12 & 1.0 \\
\hline$>1$ day & 813 & 38.0 & 9 & 1.1 \\
\hline
\end{tabular}

$*$ Rate $=$ infections $/ 100$ operations

** Others: Penicillin, amoxicillin, amoxicillin/clavulanate, ampicillin, cloxacillin, cefazolin, cephalexin, cefotaxime, ceftriaxone, ceftazidime, cefdinir, cefoxitin, ofloxacin, norfloxacin, cotrimoxazole, chloramphenical, fosfomycin, clindamycin, and amikacin.

*** Median $=\mathrm{I}$ day (interquartile range $\mathrm{I}-2$ days)

\section{Efficacy of antibiotic prophylaxis}

Antibiotic prophylaxis was associated with decreased risk of SSI, while timing of administration - preoperatively vs. intraoperatively - had no effect on risk. Compared with no antibiotic prophylaxis, receiving one-day, or multipleday antibiotic prophylaxis was each associated with about one third of the SSI risk, adjusted RR were $0.30(0.11-$ 0.88 ) and $0.32(0.10-0.98)$, respectively (Table 3$)$. This reduced risk was also found when receiving only a single dose of metronidazole in combination with gentamycin (adjusted RR $=0.28(0.09-0.90))$, Data on duration, administration time, and antibiotic agent associated with SSI, adjusted for age, sex, ASA score, and duration of operation, are shown in Table 3.

\section{Discussion}

This prospective cohort study conducted in eight Thai hospitals showed that a prolonged duration of operation was a significant risk factor for SSI among patients undergoing appendectomy. Conversely, antibiotic prophylaxis was inversely related to the risk of SSI in such uncomplicated appendicitis patients. Single-day antibiotic prophylaxis was found to be as effective as multiple-day antibiotic prophylaxis in reducing SSIs and administering prophylaxis before the incision or intraoperatively did not affect the risk. A combined single dose of metronidazole and gentamicin seemed sufficient to reduce risk of SSI in uncomplicated appendicitis patients.

\section{Study strengths and weaknesses}

The strengths of this study are its large sample size and prospective cohort design with complete early follow-up. Furthermore, we were able to include all patients admitted with uncomplicated appendicitis, who underwent open surgery in all of the eight hospitals.

Among the study limitations was the failure to account for differences in surgical technique, preoperative and postoperative practices. However, appendectomies are performed quite uniformly in Thailand and we consider large variation in these practices unlikely. Owing to high cost of post-discharge surveillance, we were unable to follow all patients for 30 days after surgery. Curtailed follow-up may cause underestimation of the SSI rate. Still, the SSI rate in our study $(1.2 \%)$ was similar to that observed in the NNIS system report (1.3\%) [2]. Some SSIs were potentially misclassified when the exact layer of tissue or organ/space involved in the infection was unclear. To limit such misclassification, an expert was consulted in these cases. In addition, the surgeon and at least one person from the infection control team had to agree to the diagnosis and classification of SSI in all cases.

\section{Risk factors}

A prolonged duration of operation has been reported as a risk factor for SSI in other studies [1,23,24]. Earlier investigations have also reported increasing age [25], and emer- 
Table 3: Association between surgical site infections and duration, timing, and antibiotic prophylaxis agent, adjusted for age, sex, ASA score, and duration of operation

\begin{tabular}{|c|c|c|c|c|c|c|c|}
\hline \multirow[t]{2}{*}{ Predictor variable } & \multirow[t]{2}{*}{$\mathbf{N}$} & \multirow[t]{2}{*}{ Infection } & \multirow[t]{2}{*}{ Rate* } & \multicolumn{4}{|c|}{ Relative risk } \\
\hline & & & & Crude & $95 \% \mathrm{Cl}$ & Adjusted** & $95 \% \mathrm{Cl}$ \\
\hline \multicolumn{8}{|l|}{ Duration of antibiotic prophylaxis } \\
\hline None & 167 & 5 & 3.0 & 1.00 & Reference & 1.00 & Reference \\
\hline I day & 1159 & 12 & 1.0 & 0.34 & $0.12-0.97$ & 0.30 & $0.10-0.88$ \\
\hline$>$ I day & 813 & 9 & 1.1 & 0.36 & $0.12-1.09$ & 0.32 & $0.10-0.98$ \\
\hline \multicolumn{8}{|l|}{ Time of first antibiotic dose administration } \\
\hline None & 167 & 5 & 3.0 & 1.00 & Reference & 1.00 & Reference \\
\hline$>$ I hour preoperatively & 1004 & 8 & 0.8 & 0.26 & $0.08-0.81$ & 0.22 & $0.07-0.70$ \\
\hline$\leq \mathrm{I}$ hour preoperatively or interoperation & 814 & 9 & 1.1 & 0.36 & $0.12-1.09$ & 0.33 & $0.11-1.02$ \\
\hline Postoperatively & 154 & 4 & 2.6 & 0.86 & $0.23-3.28$ & 0.78 & $0.20-3.00$ \\
\hline \multicolumn{8}{|l|}{ Antibiotic agent } \\
\hline None & 167 & 5 & 3.0 & 1.00 & Reference & 1.00 & Reference \\
\hline Single dose combination metronidazole and gentamicin & 766 & 8 & 1.0 & 0.34 & $0.11-1.06$ & 0.28 & $0.09-0.90$ \\
\hline Combination metronidazole and gentamicin within I day & 130 & I & 0.8 & 0.25 & $0.03-2.18$ & 0.22 & $0.03-1.98$ \\
\hline Combination metronidazole and gentamicin $>1$ day & 370 & 4 & 1.1 & 0.35 & $0.09-1.34$ & 0.29 & $0.08-1.12$ \\
\hline Others*** & 706 & 8 & 1.1 & 0.37 & $0.12-1.15$ & 0.37 & $0.12-1.15$ \\
\hline
\end{tabular}

$*$ Rate $=$ infections $/ 100$ operations

** Adjusted for age, sex, ASA score, and duration of operation

**** Others: Penicillin, amoxicillin, amoxicillin/clavulanate, ampicillin, cloxacillin, cefazolin, cephalexin, cefotaxime, ceftriaxone, ceftazidime, cefdinir, cefoxitin, ofloxacin, norfloxacin, cotrimoxazole, chloramphenical, fosfomycin, clindamycin, and amikacin.

gency surgery [26] as risk factors of SSI. Our study did not show substantial association between these factors and the risk of SSI. Under-accounting for other predictors of SSI not included in our analysis might explain our failure to observe an association between age or emergency surgery and SSI.

\section{The use of antibiotic prophylaxis}

Twenty-one different antibiotic agents were administered to appendectomy patients in our study, highlighting the lack of consensus among Thai surgeons in prescribing practices. Metronidazole plus gentamicin were most commonly used agents, and our study confirmed their effectiveness in reducing SSIs reported by others $[18,19]$. The prophylaxis was effective despite the fact that timing of prophylaxis followed international guidelines in only $39 \%$ of the cases $[27,28]$. This finding corroborates the notion that the timing of the administration - pre-, intraor post-operation - may not be crucial for preventing SSIs [1]. At the same time, higher SSI rate was reported among patients who received antibiotic prophylaxis after surgical incision [29], probably because the antibiotic serum concentration at the surgical closure is strongly associated with SSI [30].

The American Society of Health System Pharmacists (ASHP) [27] recommends prophylaxis with cephalosporins for uncomplicated appendicitis [27,28], with metronidazole and gentamicin only considered an alternative in cases of penicillin allergy. However, the combination of metronidazole plus gentamicin may have an economic advantage. A Thai study indicated that the estimated cost for these combined agents was 210 baht per 24 hours, compared with 1160 baht for cefoxitin [31]. Adverse effects were not documented for our patients.

Extended duration of antibiotic prophylaxis was less frequent in our study than in a Malaysian study [32], but our finding is consistent with other studies conducted in France [8] and Spain [9].

The improper use of antibiotic agents and inappropriately prolonged duration of antibiotic prophylaxis are likely to cause antimicrobial resistance [33-38]. Surgeons and surgical departments need to update their practices of antibiotic prophylaxis to comply with standard guidelines $[27,28]$ and updated evidencebase [1].

\section{Efficacy of antibiotic prophylaxis}

Antibiotic prophylaxis is associated with a decreased risk of postoperative SSIs. This finding is in agreement with other studies [4,14-19]. In addition, our data indicate that in uncomplicated appendicitis cases, one-day antibiotic prophylaxis is just as effective in reducing SSIs as multipleday antibiotic prophylaxis. Thus, our study does not offer justification for routine administration of oral antibiotics upon hospital discharge as in a previous study [39]. Furthermore, our findings correspond to findings in other reports $[27,40]$, a single-dose antibiotic [40], such a combined a single dose of metronidazole and gentamicin, was efficient to reduce SSIs in uncomplicated appendicitis [27]. 


\section{Conclusion}

A prolonged duration of operation was associated with increased risk of SSI among appendectomy patients, while antibiotic prophylaxis was associated with decreased risk. A combined a single dose of metronidazole and gentamicin administered preoperatively or intraoperatively appears sufficient to reduce SSIs in patients with uncomplicated appendicitis. We recommend that preoperative antibiotic prophylaxis be administered to all patients undergoing appendectomy.

\section{Abbreviations}

SSI Surgical site infection

NNIS National Nosocomial Infection Surveillance

ASA American Society of Anesthesiologists

RR Relative risk

CI Confidence intervals

\section{Competing interests}

The author(s) declare that they have no competing interests.

\section{Authors' contributions}

HTS, NK and MN conceptualized the study. NK and the Surgical Site Infection Study Group assisted with the data collection. NK was responsible for data management and data analysis. HTS, NK, MN and HCS were responsible for interpretation of data. HTS, MN, HCS, SJ and VC provided advice and review. NK, HTS, MN, HCS, SJ and VC collaboratively wrote the manuscript. All authors read and approved the final manuscript.

\section{Acknowledgements}

We thank the directors of the participating hospitals, infection control nurses, hospital ward and other clerical staff, and others who assisted with data collection. This work was funded by The Royal Golden Jubilee Ph.D. Program of the Thailand Research Fund.

\section{References}

I. Andersen BR, Kallehave FL, Andersen HK: Antibiotics versus placebo for prevention of postoperative infection after appendicectomy. Cochrane Database Syst Rev 2005, 3:CD00I439.

2. National Nosocomial Infections Surveillance (NNIS) System Report, data summary from January 1992 through June 2004, issued October 2004. Am J Infect Control 2004, 32:470-485.

3. Hale DA, Molloy M, Pearl RH, Schutt DC, Jaques DP: Appendectomy: a contemporary appraisal. Ann Surg 1997, 225:252-26I.

4. Koch A, Zippel R, Marusch F, Schmidt U, Gastinger I, Lippert H: Prospective multicenter study of antibiotic prophylaxis in operative treatment of appendicitis. Dig Surg 2000, I 7:370-378.

5. Dellinger EP, Gross PA, Barrett TL, Krause PJ, Martone WJ, McGowan JE Jr, Sweet RL, Wenzel RP: Quality standard for antimicrobial prophylaxis in surgical procedures. Infectious Diseases Society of America. Clin Infect Dis 1994, 1 8:422-427.

6. Gyssens IC, Geerligs IE, Nannini-Bergman MG, Knape JT, Hekster YA, van der Meer JW: Optimizing the timing of antimicrobial prophylaxis in surgery: an intervention study. I Antimicrob Chemother 1996, 38:301-308.

7. Silver A, Eichorn A, Kral J, Pickett G, Barie P, Pryor V, Dearie MB: Timeliness and use of antibiotic prophylaxis in selected inpatient surgical procedures. The Antibiotic Prophylaxis Study Group. Am J Surg 1996, I 7 I:548-552.

8. Bedouch P, Labarere J, Chirpaz E, Allenet B, Lepape A, Fourny M, Pavese P, Girardet P, Merloz P, Saragaglia D, Calop J, Francois P: Compliance with guidelines on antibiotic prophylaxis in total hip replacement surgery: results of a retrospective study of 416 patients in a teaching hospital. Infect Control Hosp Epidemiol 2004, 25:302-307.

9. Pons-Busom M, Aguas-Compaired M, Delas J, Eguileor-Partearroyo B: Compliance with local guidelines for antibiotic prophylaxis in surgery. Infect Control Hosp Epidemiol 2004, 25:308-312.

10. Dahms RA, Johnson EM, Statz CL, Lee JT, Dunn DL, Beilman GJ: Third-generation cephalosporins and vancomycin as risk factors for postoperative vancomycin-resistant enterococcus infection. Arch Surg 1998, I 33: I343-I346.

II. Lau WY, Fan ST, Chu KW, Suen HC, Yiu TF, Wong KK: Randomized, prospective, and double-blind trial of new betalactams in the treatment of appendicitis. Antimicrob Agents Chemother 1985, 28:639-642.

12. Liberman MA, Greason KL, Frame S, Ragland J): Single-dose cefotetan or cefoxitin versus multiple-dose cefoxitin as prophylaxis in patients undergoing appendectomy for acute nonperforated appendicitis. J Am Coll Surg 1995, 180:77-80.

13. Soderquist-Elinder C, Hirsch K, Bergdahl S, Rutqvist J, Frenckner B: Prophylactic antibiotics in uncomplicated appendicitis during childhood - a prospective randomised study. Eur J Pediatr Surg 1995, 5:282-285.

14. Nguyen BL, Raynor S, Thompson JS: Selective versus routine antibiotic use in acute appendicitis. Am Surg 1992, 58:280-283.

15. Gorecki P, Schein M, Rucinski JC, Wise L: Antibiotic administration in patients undergoing common surgical procedures in a community teaching hospital: the chaos continues. World J Surg 1999, 23:429-432.

16. Tonz M, Schmid P, Kaiser G: Antibiotic prophylaxis for appendectomy in children: critical appraisal. World J Surg 2000, 24:995-998

17. Charalambous C, Tryfonidis M, Swindell R, Lipsett AP: When should old therapies be abandoned? A modern look at old studies on topical ampicillin. J Infect 2003, 47:203-209.

18. Lau WY, Fan ST, Chu KW, Yip WC, Yiu TF, Yeung C, Wong KK: Cefoxitin versus gentamicin and metronidazole in prevention of post-appendicectomy sepsis: a randomized, prospective trial. J Antimicrob Chemother 1986, I 8:613-619.

19. al Dhohayan A, al Sebayl M, Shibl A, al Eshalwy S, Kattan K, al Saleh $M$ : Comparative study of augmentin versus metronidazole/ gentamicin in the prevention of infections after appendicectomy. Eur Surg Res 1993, 25:60-64.

20. Horan TC, Gaynes RP, Martone WJ, Jarvis WR, Emori TG: CDC definitions of nosocomial surgical site infections, 1992: a modification of CDC definitions of surgical wound infections. $\mathrm{Am} J$ Infect Control 1992, 20:271-274.

21. Owens WD, Felts JA, Spitznagel EL Jr: ASA physical status classifications: a study of consistency of ratings. Anesthesiology 1978, 49:239-243.

22. Culver DH, Horan TC, Gaynes RP, Martone WJ, Jarvis WR, Emori TG, Banerjee SN, Edwards JR, Tolson JS, Henderson TS, Hughes JM, the National Nosocomial Infections Surveillance System, Atlanta, Georgia: Surgical wound infection rates by wound class, operative procedure, and patient risk index. National Nosocomial Infections Surveillance System. Am J Med I99I, 91(3B): I52S-157S.

23. Razavi SM, Ibrahimpoor M, Sabouri KA, Jafarian A: Abdominal surgical site infections: incidence and risk factors at an Iranian teaching hospital. BMC Surg 2005, 5:2.

24. Hernandez K, Ramos E, Seas C, Henostroza G, Gotuzzo E: Incidence of and risk factors for surgical-site infections in a Peruvian hospital. Infect Control Hosp Epidemiol 2005, 26:473-477.

25. Kaye KS, Schmit K, Pieper C, Sloane R, Caughlan KF, Sexton DJ, Schmader KE: The effect of increasing age on the risk of surgical site infection. J Infect Dis 2005, 191:1056-1062.

26. Sohn AH, Parvez FM, Vu T, Hai HH, Bich NN, Le Thu TA, Le Hoa TT, Thanh NH, Viet TV, Archibald LK, Banerjee SN, Jarvis WR: Preva- 
lence of surgical-site infections and patterns of antimicrobial use in a large tertiary-care hospital in Ho Chi Minh City, Vietnam. Infect Control Hosp Epidemiol 2002, 23:382-387.

27. ASHP Therapeutic Guidelines on Antimicrobial Prophylaxis in Surgery: American Society of Health-System Pharmacists. Am J Health Syst Pharm 1999, 56:1839-1888.

28. Mangram AJ, Horan TC, Pearson ML, Silver LC, Jarvis WR: Guideline for Prevention of Surgical Site Infection, 1999. Centers for Disease Control and Prevention (CDC) Hospital Infection Control Practices Advisory Committee. Am J Infect Control 1999, 27:97-132.

29. Classen DC, Evans RS, Pestotnik SL, Horn SD, Menlove RL, Burke JP. The timing of prophylactic administration of antibiotics and the risk of surgical-wound infection. N Engl J Med 1992, 326:28I-286.

30. Zelenitsky SA, Ariano RE, Harding GK, Silverman RE: Antibiotic pharmacodynamics in surgical prophylaxis: an association between intraoperative antibiotic concentrations and efficacy. Antimicrob Agents Chemother 2002, 46:3026-3030.

31. Sunpaweravong S: Practice guidelines for prophylactic antibiotic. Songkla Med J 1999, 17:225-229.

32. Gul YA, Hong LC, Prasannan S: Appropriate antibiotic administration in elective surgical procedures: still missing the message. Asian J Surg 2005, 28: 104-108.

33. Paterson DL, Rossi F, Baquero F, Hsueh PR, Woods GL, Satishchandran V, Snyder TA, Harvey CM, Teppler H, Dinubile MJ, Chow JW: In vitro susceptibilities of aerobic and facultative Gram-negative bacilli isolated from patients with intra-abdominal infections worldwide: the $\mathbf{2 0 0 3}$ Study for Monitoring Antimicrobial Resistance Trends (SMART). J Antimicrob Chemother 2005, 55:965-973.

34. Kusum M, Wongwanich S, Dhiraputra C, Pongpech P, Naenna P: Occurrence of extended-spectrum beta-lactamase in clinica isolates of Klebsiella pneumoniae in a University Hospital, Thailand. J Med Assoc Thai 2004, 87: 1029-1033.

35. Girlich D, Naas T, Leelaporn A, Poirel L, Fennewald M, Nordmann P: Nosocomial spread of the integron-located veb-I-like cassette encoding an extended-pectrum beta-lactamase in Pseudomonas aeruginosa in Thailand. Clin Infect Dis 2002, 34:603-6II.

36. Girlich D, Poirel L, Leelaporn A, Karim A, Tribuddharat C, Fennewald $M$, Nordmann P: Molecular epidemiology of the integronlocated VEB-I extended-spectrum beta-lactamase in nosocomial enterobacterial isolates in Bangkok, Thailand. J Clin Microbiol 200I, 39: 175-182.

37. Biedenbach DJ, Johnson DM, Jones RN: In vitro evaluation of cefepime and other broad-spectrum beta-lactams in eight medical centers in Thailand. The Thailand Antimicrobial Resistance Study Group. Diagn Microbiol Infect Dis 1999, 35:325-331.

38. Teng LJ, Hsueh PR, Tsai JC, Liaw SJ, Ho SW, Luh KT: High incidence of cefoxitin and clindamycin resistance among anaerobes in Taiwan. Antimicrob Agents Chemother 2002, 46:2908-29I3.

39. Taylor E, Berjis A, Bosch T, Hoehne F, Ozaeta M: The efficacy of postoperative oral antibiotics in appendicitis: a randomized prospective double-blinded study. Am Surg 2004, 70:858-862.

40. Mui LM, Ng CS, Wong SK, Lam YH, Fung TM, Fok KL, Chung SS, Ng EK: Optimum duration of prophylactic antibiotics in acute non-perforated appendicitis. ANZ J Surg 2005, 75:425-428.

\section{Pre-publication history}

The pre-publication history for this paper can be accessed here:

http://www.biomedcentral.com/1471-2334/6/111/pre pub
Publish with Biomed Central and every scientist can read your work free of charge

"BioMed Central will be the most significant development for disseminating the results of biomedical research in our lifetime. "

Sir Paul Nurse, Cancer Research UK

Your research papers will be:

- available free of charge to the entire biomedical community

- peer reviewed and published immediately upon acceptance

- cited in PubMed and archived on PubMed Central

- yours - you keep the copyright
BioMedcentral 